Vol. 11, No. 1, 2021

\title{
SPUTTERING RATE OF LEAD, TIN AND GERMANIUM TELLURIDES WITH LOW ENERGY ARGON IONS
}

\author{
Dmytro Zayachuk ${ }^{1}$, Vasyl Slynko ${ }^{2}$, Attila Csík ${ }^{3}$ \\ ${ }^{1}$ Lviv Polytechnic National University, Lviv, Ukraine \\ ${ }^{2}$ Institute for Problems of Material Science NASU, Chernivtsy Branch, Chernivtsy, Ukraine \\ ${ }^{2}$ Institute for Nuclear Research, (ATOMKI), H-4026 Debrecen, Bem sqr 18/c, Hungary \\ zayachuk@polynet.lviv.ua
}

\begin{abstract}
Sputtering of $\mathrm{PbTe}$, SnTe, and GeTe crystal samples by low-energy Ar+ ions are investigated, and the sputtering rate $v_{s p}$ of the studied compounds, as well as its dependence on both the composition of crystal matrix and the sputtering energy are determined. It is found that under the same conditions the sputtering rate in the sequence of GeTe-SnTe-PbTe telluride compounds increases when their average atomic weight increases. This phenomenon is explained by changes in the surface binding energy of metal atoms in lead, tin and germanium tellurides. It is shown that for all compounds the sputtering rate also increases with the increase in the sputtering energy. In the energy range from 160 to $550 \mathrm{eV}$, this increase is almost linear. The coefficients of change in the sputtering rate with energy $\mathrm{d} v_{s p} / \mathrm{d} E$ are calculated. The surface density of $\mathrm{Ar}+$ ioninduced structures and the relative area of the sputtered surface covered by these structures are determined for the natural lateral surfaces of a PbTe crystal grown from melt by the Bridgman method as a function of sputtering energy. It is shown that both studied parameters decrease exponentially with increasing the sputtering energy.
\end{abstract}

Key words: Sputtering; Sputtering rate; $\mathrm{PbTe}$; SnTe; GeTe

\section{Introduction}

Sputtering of solids with energetic ion beams is widely used for various applications, in particular for determining the composition and dept distribution of elements in layered structures by Secondary Neutral Mass Spectrometry (SNMS) method [1]. To determine the distribution of components in a multi-element sample by the SNMS method, the sample profiling to a significant depth must be carried out. Profiling of solids by ion beams, especially in case of multi-component materials, leads to the formation of a complex topology of the sputtered surfaces. Formation of such structures strongly depends on the composition of the samples, the method of their growing and treatment, the state of the initial surface, the sputtering parameters, etc. (see, for example, reviews [2,3] and references). Our research over the last few years have been shown that all of this is fully applied also to IV-VI semiconductors PbTe, SnTe, and GeTe [4-10]. In particular, we found that the specificity of formation of the sputtered surface of $\mathrm{PbTe}$ crystals due to the processes of re-deposition of sputtered species leads to i) the phenomenon of aperiodical oscillations of $\mathrm{Pb}$ and $\mathrm{Te}$ sputtering $[4,5]$; ii) the morphology of the sputtering surfaces and the differences in the constituent masses of $\mathrm{PbTe}, \mathrm{SnTe}$, and GeTe cause the changes in the relative detection factor of the compound intrinsic constituents, due to which there is no unambiguous relationship between the ratio of concentrations of the telluride components and the ratio of the intensity of their sputtered signals; to solve the problem of quantitative determination of composition, it is necessary to introduce an adjustment to the magnitude of the relative detection factor, which depends on the sputtered surface morphology, the $\mathrm{Ar}^{+}$ ions energy bombarding the surface and must be determined separately in each individual case [6-8]; iii) sputtering by low energy $\mathrm{Ar}^{+}$ions causes amorphisation effect on the surface of SnTe and GeTe crystals [9]; iv) near-non-preferential sputtering of SnTe surface leads to formation of sputtered surface always covered with a dense array of cones of nanometer range of height [10].

To successfully use the ion sputtering for different practical applications, it is useful to know the sputtering rate for different materials at different ions energies. With regard to the semiconductor compounds being to the focus of our recent research, this issue has not been systematically investigated. Therefore, this work is intended to fill the existing gap and is devoted to the study of the sputtering rate of crystal surfaces of PbTe, $\mathrm{SnTe}$, and GeTe compounds by $\mathrm{Ar}^{+}$ions in the lowenergy range (from a few tens to a few hundred $\mathrm{eV}$ ), which is typically used in the SNMS method.

\section{Experimental details}

In this study we investigated the $\mathrm{PbTe}, \mathrm{SnTe}$, and GeTe semiconductor compounds. The samples for investigation were cut from ingots synthesized or grown by Bridgman method from high-purity initial materials. Their composition was verified by Energy-Dispersive $\mathrm{X}$-ray Spectroscopy (EDX) analysis. In all cases, the 
composition of the samples corresponded to the stoichiometric ratio. Sputtering experiments were carried out on INA-X type Secondary Neutral Mass Spectrometry system produced by SPECS GmbH, Berlin. The surface bombardment and post-ionization of sputtered neutral particles were done by the Electron Cyclotron Wave Resonance argon plasma. For the plasma to be initialized, $150 \mathrm{~W}$ of RF power was applied at the $1 \cdot 10^{-3}$ mbar Ar gas pressure. In the direct bombardment mode, $\mathrm{Ar}^{+}$ions are extracted from low pressure plasma and bombard a negatively sample surface with a current density of $\sim 1 \mathrm{~mA} / \mathrm{cm}^{2}$, performing a controlled surface erosion. The sputtering energy used in our experiments is changed from 50 to $550 \mathrm{eV}$. The sputtered area was confined to a circle of $2 \mathrm{~mm}$ in diameter by a Ta mask. The surface topology was analyzed by Scanning Electron Microscopy (SEM) (Hitachi S-4300 CFE). Processing of digital images of the surface structures forming by sputtering the surface with an ion beam was performed using software Image J [11], which allows reading many image formats, including BMP format, in which the SEM images of the sputtered surfaces were kept.

\section{Results}

As we pointed in the introductory part, the main focus of this study is to determine the sputtering rate of $\mathrm{PbTe}, \mathrm{SnTe}$, and GeTe samples with $\mathrm{Ar}^{+}$ions of different energy. Samples with different surfaces are needed for practical application. Therefore, two types of sample surfaces of the studied compounds were used for the determination of sputtering rate. The natural surfaces formed in the process of crystal growth and the surfaces treated mechanically were sputtered in the case of PbTe. In the case of other two compounds (SnTe and GeTe), the sputtering experiments were carried out on machined surfaces.

A general view of PbTe sputtered surfaces on the example of two samples sputtered with $\mathrm{Ar}^{+}$ions of energy of $350 \mathrm{eV}$ during 50 minutes is shown in Fig. 1. Naturally, it is cardinally different for the surfaces of various origins. The sputtered lateral surface of the crystal ingot grown from melt by the Bridgman method is quite smoothed. Only dimples of the surface relief and a few of the residual structures one can see on it (Fig. 1a). Instead, the sputtered mechanically treated surface has a rich wavy structure resembling a microscopic image of an un-sputtered surface. Additionally, there are many cone-shaped structures of different heights, in particular truncated cones. A characteristic feature of these truncated conical shapes is a pronounced difference in contrast of SEM images of the cone apexes and body. This contrast difference indicates that the chemical composition on these places is also different. It is obviously due to the fact that the grains of powders used in the process of the crystal cutting remain into the surface layers of cut plates. These grains act as protective shields for the surface areas covered by them. However, as can be clearly seen, the difference in the topology of sputtered crystal surfaces of different origin has almost no effect on the height of the ledge at the boundary between the sputtered and un-sputtered areas (see the numerical data in Fig. 1). Within the experimental error, the average values of the sputtering depth (the ledge height) agree well with each other. So, we can use the height of this ledge for the sputtered surface of any origin for the determination of the sputtering rate of materials studied.

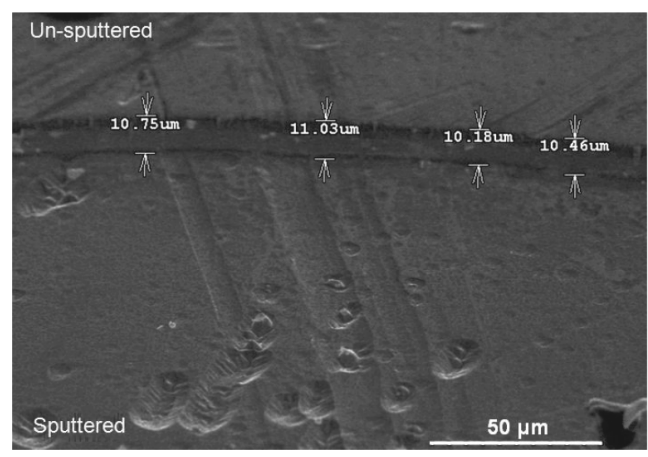

a)

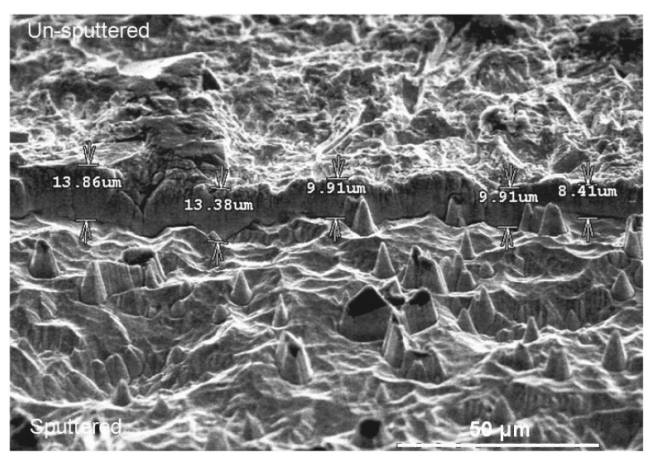

b)

Fig. 1. SEM images at $60^{\circ}$ tilt of the natural lateral surface of a PbTe crystal grown from melt by the Bridgman method (a) and the mechanically treated surface $(b)$, which are sputtered by an Ar+ ion beam with energy of $350 \mathrm{eV}$ during $50 \mathrm{~min}$. It is indicated the visible height of the ledge separating the sputtered and un-sputtered areas measured at different points.

The sputtering rate was determined as a ratio of the ledge height at the boundary between the sputtered and un-sputtered areas to the sputtering time. As all SEM images were done at the tilt projection, where the angle of tilt $\delta$ was equal to $60^{\circ}$, the measured value of the height is its visible $h_{v}$ value projected on the plane perpendicular to the direction of the SEM image. The actual height of the ledge $h_{a}$ is greater than its visible value and was defined as $h_{a}=h_{v} / \sin \delta$.

For SnTe and GeTe only the mechanically treated surfaces were used for the sputtering experiment. Fig. 2 shows the SEM images of such surfaces sputtered under 
the same conditions as the PbTe surfaces presented in Fig. 1. They are similar to the sputtered mechanically treated PbTe surface (Fig. 1, b). But the height of boundary ledges for these compounds is smaller compared with $\mathrm{PbTe}$. It means that the sputtering rate for SnTe and GeTe is also smaller than in the case of PbTe.

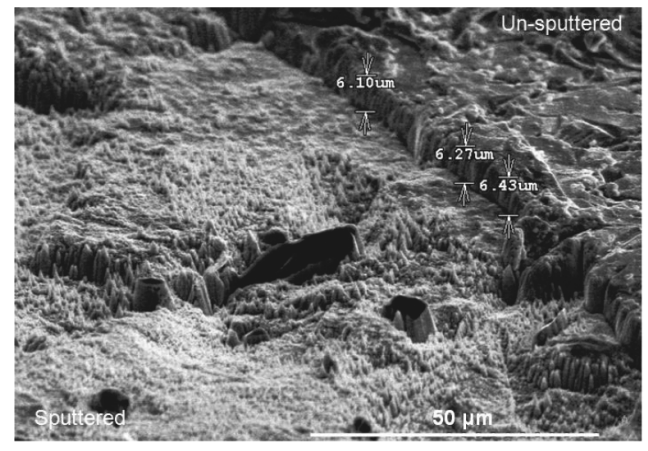

a)

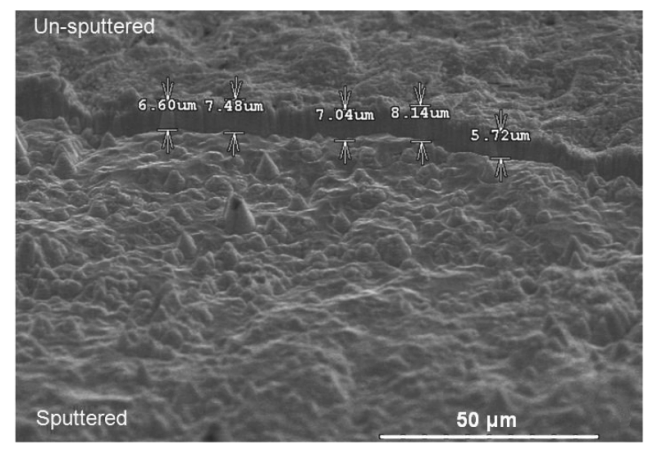

b)

Fig. 2. SEM images at $60^{\circ}$ tilt of the sputtered mechanically treated SnTe (a) and GeTe (b) surfaces. Conditions on sputtering and marking are the same as in Fig. 1.

Using the average values of the ledge height at the boundary between the sputtered and un-sputtered areas for the different sputtering energies and duration, the dependence of the sputtering rate $v_{s p}$ on the sputtering energy for the different compounds was determined. The obtained data are shown in Fig. 3. They allow us to draw the following general conclusions:

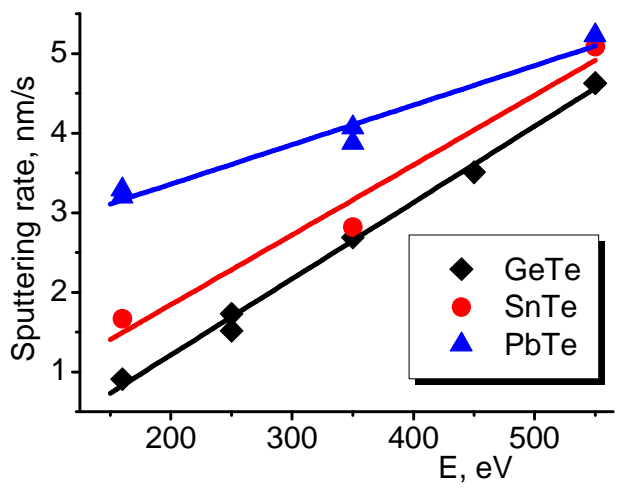

Fig. 3. Sputtering rate of $(\mathrm{Pb}, \mathrm{Sn}, \mathrm{Ge}) \mathrm{Te}$ compounds vs. sputtering energy.
- At a given sputtering energy, the sputtering rate in the sequence of GeTe-SnTe-PbTe compounds increases in the direction from the compound with a lighter atom to that with a heavier one of the metal component, i.e. with increasing the average atomic weight of the compound.

- With the sputtering energy increasing, the sputtering rate, naturally, increases for all compounds. Within the experimental error, this increase can be satisfactorily extrapolated by a linear dependence.

- The average atomic mass of the compound increasing, the changes in the sputtering rate with the sputtering energy weaken. The coefficient of change in the sputtering rate with the sputtering energy $\mathrm{d} v_{\mathrm{sp}} / \mathrm{dE}$ acquires the following values: $8.3 \cdot 10^{-3} \mathrm{~nm} / \mathrm{s} \cdot \mathrm{eV}$ for GeTe, $7.6 \cdot 10^{-3} \mathrm{~nm} / \mathrm{s} \cdot \mathrm{eV}$ for SnTe and $4.3 \cdot 10^{-3} \mathrm{~nm} / \mathrm{s} \cdot \mathrm{eV}$ for $\mathrm{PbTe}$.

Also, we can see in Fig. 3 the tendency to converge the sputtering rate of the compounds at high sputtering energies. To more clearly demonstrate this, in Fig. 4, the ratio of the sputtering rate of heavier compounds $\mathrm{PbTe}$ and SnTe to the lightest one GeTe is shown. As it is seen, this ratio decreases almost four times for the pair of $\mathrm{PbTe} / \mathrm{GeTe}$ and almost two times for the pair of $\mathrm{SnTe} / \mathrm{GeTe}$ in the studied energy range of $160-550 \mathrm{eV}$.

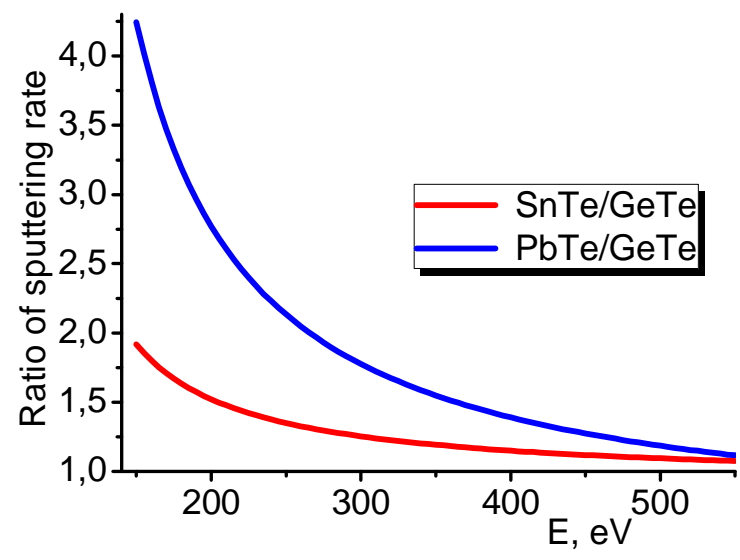

Fig. 4. The ratio of the sputtering rate of $\mathrm{SnTe} / \mathrm{GeTe}$ and PbTe/GeTe vs. sputtering energy.

By processing digital SEM images of the sputtered natural PbTe surfaces by using software ImageJ, the surface density of ion-induced structures, the relative area of the sputtered surface covered by the surface structures and their dependence on the sputtering energy were determined.

Since the ion-induced surface structures are distributed over the sputtered surface rather inhomogeneously, the latter was divided into a large number of segments, each of which was counted separately. The final results were averaged taking into account the share of each segment in the total area of the 
sputtered surface. The results of the counts are presented in Fig. 5 in terms of the dependence of the surface density $\rho$ of the ion-induced surface structures on the sputtering energy. As it can be seen, at constant sputtering time, the density of ion-induced surface structures decreases when sputtering energy increases and tends to some constant value. The law of density decrease with a sputtering energy can be well described by exponential dependence $\rho(E)=A+B \exp (-E / C)$. For the case shown in Fig. $5 A=3 \cdot 10^{4} \mathrm{~cm}^{-2}$, $B=1.08 \cdot 10^{6} \mathrm{~cm}^{-2}, \mathrm{C}=35 \mathrm{eV}$.

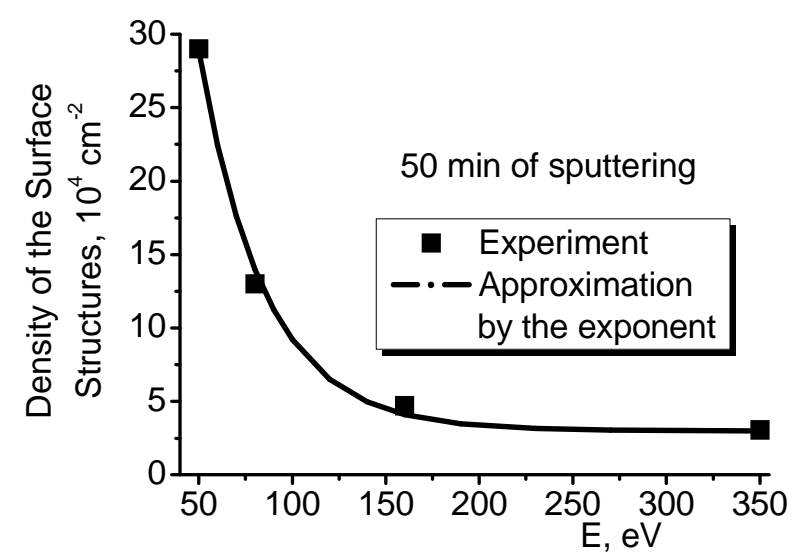

Fig. 5. Surface density of $\mathrm{Ar}^{+}$ion-induced surface structures on the natural lateral surface of a PbTe crystal grown from melt by the Bridgman method vs. sputtering energy.

The dependence of the relative area of sputtered surface covered with ion-induced surface structures on sputtering energy is shown in Fig. 6.

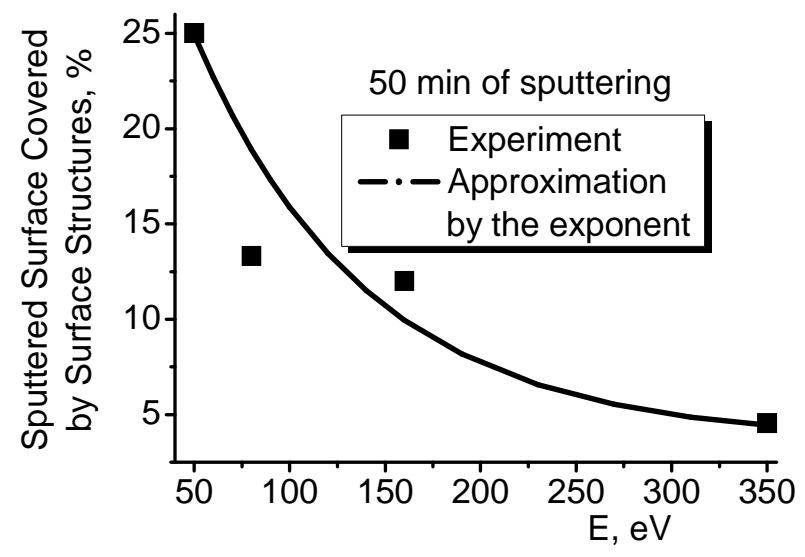

Fig. 6. The relative area of the sputtered natural lateral surface of PbTe crystal grown from melt by the Bridgman method covered with ion-induced surface structures vs. sputtering energy.

Behavior of the relative area $\Delta S / S$ of the sputtered surface covered with surface structures resembles the behavior of the structures surface density $\rho$. It can also be satisfactorily described by exponential dependence $\Delta S / S(E)=A+B \exp (-E / C)$, but the rate of decreasing
$\Delta S / S(E)$ is much less, i.e. the parameter $C$ is much greater. In this particular case $C=90 \mathrm{eV}$. When the sputtering energy increased from 50 to $350 \mathrm{eV}$, the density of ion-induced surface structures for the investigated surface decreased by about 10 times, and the relative area covered with the structures - twice less, i.e. 5 times.

\section{Discussion}

Sputtering of solids is the process of erosion of a target arising due its bombardment by energetic ions. In the frame of Sigmund's linear collision cascade theory [12], sputtering develops as a result of a collision cascade, which is provoked by ions falling on the surface and penetrating into the target involving many target atoms. The atoms involved in the collision cascade can fly outside through the entrance surface, what forms sputtering of a target. Many different factors affect the sputter yield, defined as the number of emitted atoms per incoming ion, and, accordingly, the rate of sputtering of solids, in particular, the angle of ion incidence on the surface [12]. As the sputtering rate is the rate corresponding to normal incidence of ions onto the sputtering surface, using the ledge height at the boundary between the sputtered and un-sputtered areas of surface is very suitable for its determination as the presence of a tantalum protective mask prevents the appearance of inclined sliding of ions along this boundary.

Let us first analyze the obtained experimental results from the point of view of the ratio between the sputtering rates of the compounds studied. As shown above, in the sequence of GeTe-SnTe-PbTe compounds at a fixed value of the sputtering energy the inequality $v_{s p}(\mathrm{PbTe})>v_{s p}(\mathrm{SnTe})>v_{s p}(\mathrm{GeTe})$ is satisfied. To explain this seemingly surprising result, when a compound with a larger average atomic weight is sputtered faster than a compound with a smaller average atomic weight, we take into account that the sputtering rate $v_{s p}$ directly depends on the magnitude of the sputter yield $Y$. According to the linear cascade theory for $E>>U$, where $E$ is the energy of a sputtering beam and $U$ is the surface binding energy, the sputter yield $Y$ of some constituent of solid is determined by its surface concentration $N_{S}$, atomic mass $M$, and surface binding energy $U$ as:

$$
Y: N_{S} / M^{2 m} U^{1-2 m}
$$

where $m$ is the exponent in the low energy power cross section, a quantity close to zero [12]. Our recent studies [6] on patterns produced by a sputtering process have shown that in the sequence of PbTe-SnTe-GeTe tellurides, the metal atoms surface binding energy decreases in the direction from a lighter atom to a 
heavier one. So, if $U(\mathrm{~Pb})<U(\mathrm{Sn})<U(\mathrm{Ge})$, then it has to be that $v_{s p}(\mathrm{PbTe})>v_{s p}(\mathrm{SnTe})>v_{s p}(\mathrm{GeTe})$. That is exactly what we observe. Thus, the results of the studies of the sputtering rate of IVB group tellurides, which we present here, are in full agreement with the previously obtained data on the surface binding energy of the metal components of these compounds [6] and confirm them.

To explain a tendency to converge the sputtering rate of the investigated compounds at high sputtering energies (Fig. 4), take into account the fact that the energy of an ion beam must go beyond some threshold energy for sputtering a solid, and that this threshold is usually in order of $20 \mathrm{eV}$ [12]. The exact values of these threshold energies for the studied materials are unknown. But it is logical to assume that they will correlate with the surface binding energies. Therefore, it can be expected that the value of the threshold energy for sputtering in the case of PbTe will be the least, and for GeTe, on the contrary, the greatest. The closer the real sputtering energy is to the threshold value, the stronger the latter will affect the sputtering rate. Obviously, the greater is the difference between these two energies, the greater is the rate of sputtering. So, for a fixed value of the sputtering energy, the difference between it and the threshold for sputtering will be the largest for $\mathrm{PbTe}$ and the smallest for GeTe. The influence of the threshold energy on the sputtering rate will increase with decreasing the sputtering energy. Taking these two factors together, we can explain the behavior of the ratio of the sputtering rates of lead, tin and germanium telluride compounds presented in Fig. 4.

Consider now formation of ion-induced surface structures on the natural lateral surface of a PbTe crystal grown from melt by the Bridgman method. The dependence of the surface density of the stuctures on the sputtering energy is shown in Fig. 5. Formation of such structures is a common phenomenon when the surface of solid is sputtered with ion beams. Usually the different surface shapes like ripples, hillocks, cones, pyramids, pillars, rods, bumps, dots, etc. modify the topology of solid surface sputtered with energetic ions [2, 3]. According to the Bradley-Harper theory proposed to describe the process of forming surface structures under the influence of ion beam bombardment, such formation occurs due to etching of a solid surface with energy ions, the sputter yield of which depends on the local surface curvature [13]. The individual ionbombardment-induced surface shapes originate mainly, at least in the absence of seeded surface impurities, from pre-existing asperities. Such asperities can in principle be formed due to mechanical treatment, chemical treatment, inclusions, surface impurities, etc. [14]. We believe that in our case formation of such surface structures is originated due to inclusions of another phase formed in the bulk of the crystal ingot as the result of contact of the melt and the surface of the ingot crystallized from this melt with the walls of the graphitized quartz container. We make this assumption based on the results of EDX analysis, which show that the tops of the surface structures having the shape of the truncated cones are significantly enriched by $\mathrm{Si}$ and $\mathrm{C}$. Diffusion of impurities from the walls of the container into the melt during its homogenization at a high temperature above the melting point, which is $918{ }^{\circ} \mathrm{C}$ [15], leads to the establishment of some level of background impurities in the melt volume. When the melt is cooled, these impurities form microinclusions of another phase. Additional diffusion of these impurities from the walls of the container through the side surface of the ingot during its crystallization further increases their concentration in the near-surface layers relative to the background concentration. Therefore, we can expect a concentration profile of microinclusions originated by impurities, with a maximum concentration at the periphery of the ingot and the plateau in its volume. Taking into account that the greater the energy of sputtering, the greater the depth of profiling, just such distribution we see in Fig. 5.

The obtained results allow making some quantitative estimates. According to the approximation of the experimental data presented in Fig. 5, the surface density of ion-induced structures reaches a constant value when the sputtering energy reaches a value of the order of $250 \mathrm{eV}$. Taking into account the sputtering rate, presented in Fig. 4 and time of 50 minutes, we find out that the concentration of microinclusions of the other phase, which leads to the appearance of surface structures in the process of ion sputtering, reaches a constant value at a depth of the order of $10 \mu \mathrm{m}$ from the ingot surface. Herewith, according to the data in Fig. 5, the change in the concentration value of the inclusions caused by the diffusing impurities reaches one order of magnitude. Thus, we can say that in the process of growing $\mathrm{PbTe}$ crystals from the Bridgman melt in graphitized quartz containers, diffusion of basic background impurities $\mathrm{Si}$ and $\mathrm{C}$ through the side surfaces of the ingot to a depth of about $10 \mu \mathrm{m}$ takes place. It is clear that this value is not a process constant and will depend at least on the duration of the growth process, which is determined by the growth rate of the ingot and its length.

And finally, let us consider the changes of the relative area of the sputtered natural lateral surface of a $\mathrm{PbTe}$ crystal grown from melt by the Bridgman method covered with ion-induced surface structures with the change in the sputtering energy (Fig. 6). Naturally, if the concentration of the surface structures decreases with 
increasing the sputtering energy, then the fraction of a sputtered surface covered with these structures decreases too. It is noteworthy that the decreasing rate of the covered area is inferior to decreasing rate of the concentration of surface structures. In this case, this difference is approximately twofold if we compare the data in Fig. 5 and Fig. 6. This means that as the sputtering energy increases, the density of surface structures decreases, but the area of their base, which determines the fraction of the sputtered surface covered with the structures, increases. This is always the case when ioninduced surface structures are formed by the interaction of incident ion beams and a sputtered surface [2].

\section{Conclusion}

In this research, we investigate the depth profiling of $\mathrm{PbTe}, \mathrm{SnTe}$, and GeTe crystal samples by $\mathrm{Ar}^{+}$ions of different energies to determine their sputtering rate and its dependence on the sample composition and sputtering energy. It is found that in the sequence of GeTe-SnTePbTe compounds, the sputtering rate increases in the direction from the compound with a lighter atom to that with a heavier one of the metal component. These changes in the sputtering rate are explained by the dependence of the surface binding energy of the metal atoms of the studied compounds on their composition, which decreases in the direction from a lighter atom to a heavier one. It is shown that the sputtering rate depends also on the sputtering energy. If the sputtering rate increases, the latter encreases almost linearly in the energy range of 160-550 eV. The coefficient of change in the sputtering rate with the sputtering energy $d v_{s p} / d E$ depends on the compound composition and acquires the following values: $8.3 \cdot 10^{-3} \mathrm{~nm} /(\mathrm{s} \cdot \mathrm{eV})$ for GeTe, $7.6 \cdot 10^{-3} \mathrm{~nm} /(\mathrm{s} \cdot \mathrm{eV})$ for SnTe and $4.3 \cdot 10^{-3} \mathrm{~nm} /(\mathrm{s} \cdot \mathrm{eV})$ for PbTe. The obtained data can be used for planning different technological experiments involving the processes of depth profiling.

\section{References}

[1] H. Oechsner, Secondary neutral mass spectrometry (snms) and its application to depth profile and interface analysis, thin film and depth profile analysis, Ed. by Oechsner H, Springer-Verlag, pp. 63-86, 1984.

[2] O. Auciello and J. Vac. Sci. Technol. 19, 841 (1981); doi.org/10.1116/1.571224.

[3] Wai Lun Chan, Eric Chason, J. Appl. Phys. 101, 121301 (2007), https://doi.org/10.1063/1.2749198

[4] D. M. Zayachuk, E. I. Slynko, V. E. Slynko, and A. Csik, Materials Letters, 173, 167 (2016). DOI: dx.doi.org/10.1016/j.matlet.2016.03.038.
[5] Dmytro Zayachuk and Attila Csik, PbTe Crystal Sputtering and Re-deposition of Sputtered Species, (Saarbrucken, Germany: LAP Lambert Academic Publishing: 2016).

[6] D. M. Zayachuk, V. E. Slynko, and A. Csik, Mater. Sci. Semiconductor Processing, 88, 103 (2018), doi.org/10.1016/j.mssp.2018.07.037.

[7] D. M. Zayachuk, V. E. Slynko, Cs. Buga, A. Csik, Vacuum 99, 163 (2019), doi.org/10.1016/ j.vacuum.2019.02.008

[8] D. M. Zayachuk, Cs. Buga, V. E. Slynko, and A. Csík, Materials Today: Proceedings, 35, Part 4, 2021, 513-517, doi.org/10.1016/j.matpr.2019. 10.011

[9] A. Csík, D. M. Zayachuk, V. E. Slynko, U. Schmidt, Cs. Buga, and K. Vad, Materials Letters 236, 5 (2019), doi.org/10.1016/j.matlet.2018.10.061.

[10] D. M. Zayachuk, Y. D. Zayachuk, Cs. Buga, V. E. Slynko, and A. Csík, Vacuum, 186 (2021) 110058, doi.org/10.1016/j.vacuum.2021.110058.

[11] J. Broeke, J. M. M. Perez, and J.Pascau, Image Processing with ImageJ. 2nd Edition. Packt Publishing, p. 256, 2015. ISBN 978-1-78588-983-7.

[12] P. Sigmund: Elements of Sputtering Theory. In: Nanofabrication by Ion-Beam Sputtering. T. Som, D. Kanjilal. Pan Stanford Publishing, p. 1-40, 2013.

[13] R. M. Bradley and J. M. E. Harper, J. Vac. Sci. Technol. A 6, 2390 (1988), doi.org/10.1116/ 1.575561 .

[14] R. Kelly, O. Auciello,Surface Sci. 100 (1980) 135, doi.org/10.1016/0039-6028(80)90449-5.

[15] G. Nimtz and B. Schlicht, Narrow-Gap Semiconductors: Narrow Gap Lead Salts, Springer, Berlin, 1985, pp. 1-117, doi.org/ 10.1007/BFb0044919.

\section{ШВИДКІСТЬ РОЗПОРОШЕННЯ ТЕЛУРИДІВ СВИНЦЮ, ОЛОВА I ГЕРМАНІЮ ІОНАМИ АРГОНУ НИЗЬКОЇ ЕНЕРГІї}

\section{Дмитро Заячук, Василь Слинько, Attila Csík}

Досліджено розпорошення кристалів $\mathrm{PbTe}, \mathrm{SnTe}$ та $\mathrm{GeTe}$ іонами $\mathrm{Ar}^{+}$низької енергії, визначено швидкість розпорошення $v_{s p}$ та іiі залежність від складу кристалічної матриці й енергії розпорошення. Встановлено, що за однакових умов швидкість розпорошення телуридів GeTe$\mathrm{SnTe}-\mathrm{PbTe}$ зростає зі збільшенням їх середньої атомної маси. Виявлені зміни пояснено змінами поверхневої енергії зв'язку атомів металів у телуридах свинцю, олова та 
германію. Показано, що для всіх досліджуваних сполук швидкість розпорошення зростає також зі збільшенням енергії розпорошення. У діапазоні енергій від 160 до 550 еВ це збільшення майже лінійне. Розраховано коефіцієнти зміни швидкості розпорошення з енергією $d v_{s p} / d E$. Визначено поверхневу густину іонно-індукованих структур та відносну площу покритої ними розпорошеної поверхні для природних бокових поверхонь кристала $\mathrm{PbTe}$, вирощеного 3 розплаву методом Бриджмена, як функцію енергії розпорошення. Показано, що за постійного часу розпорошення обидва параметри експоненційно зменшуються зі збільшенням енергії розпорошення.

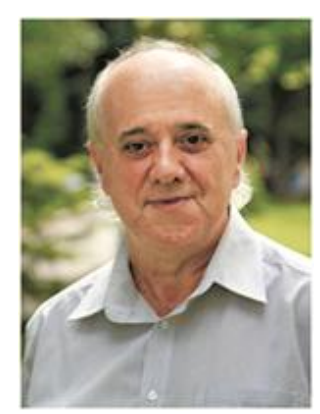

Dmytro Zayachuk, Doctor of Science, Professor, Electronics and Computer Technologies Dept., Lviv Polytechnic National University. Ph.D. in Physics - 1980, Doctor of Science in Physics - 1992, Professor title - 2001. Research interests: technology, physics and diagnostic of semiconductor bulk crystals, thin films, and nanostructures.

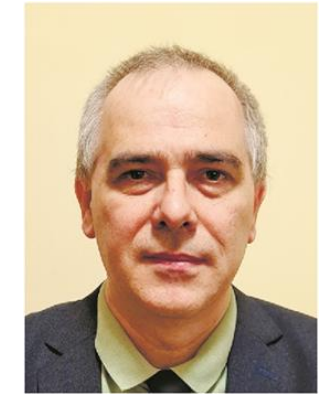

Vasyl Slynko, Head of NarrowGap Semiconductors Dept., Institute for Problems of Material Science NASU, Chernivtsy Branch, M. Sc. in Physics - 1992, Ph.D. in Physics 2008. Research interests: technology and complex studies of new IV-VI semiconductor systems and structures for spin electronics and infrared electronics.

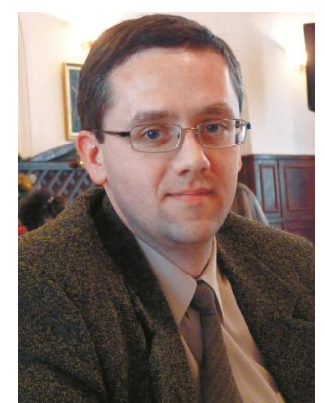

Attila Csík, Senior research, Institute for Nuclear Research, Hungary. Graduated from Lajos Kossuth University, Debrecen, 1997. PhD -University of Debrecen, 2003. Research interests: thermal stability and solid-state reaction in multilayered structures; scanning electron microscopy, secondary neutral mass spectrometry, X-ray diffraction.

Received: 21.02.2021. Accepted: 27.04.2021 